\title{
Prevalence and Risk Factors of Gastrointestinal Parasitic Infections in Small Ruminants in the Greek Temperate Mediterranean Environment
}

\author{
Vaia Kantzoura', Marc K. Kouam ${ }^{1}$, Helen Theodoropoulou ${ }^{2}$, Haralambos Feidas ${ }^{3}$, \\ Georgios Theodoropoulos ${ }^{1^{*}}$ \\ ${ }^{1}$ Department of Anatomy and Physiology of Farm Animals, Faculty of Animal Science and Aquaculture, \\ Agricultural University of Athens, Athens, Greece \\ ${ }^{2}$ Department of Home Economics and Ecology, Harokopio University, Athens, Greece \\ ${ }^{3}$ Department of Meteorology and Climatology, School of Geology, Aristotle University of Thessaloniki, \\ Thessaloniki, Greece \\ Email: "gtheo@aua.gr
}

Received December 15, 2011 ; revised January 4, 2012; accepted January 15, 2012

\begin{abstract}
Gastrointestinal (GI) parasitic infections of sheep and goats were investigated in 69 farms located in Thessaly region of Greece, characterized by temperate Mediterranean climate, during two consecutive seasons. A total of 557 fecal samples were collected. Helminth eggs were detected in 44 (7.9\%) samples. Strongyle-type eggs were found in 19 (3.4\%) samples, Nematodirus spp. eggs in $6(1.1 \%)$ samples, Trichuris spp. eggs in $16(2.9 \%)$ samples, Fasciola hepatica in 3 $(0.5 \%)$ samples, and Dicrocoelium dendriticum in $1(0.2 \%)$ sample. Coccidian oocysts were found in $36(6.5 \%)$ samples. Risk factors related to animal and farmer status, farm and pasture management, and environmental factors derived by satellite data were examined for their association with the prevalence of helmith infections. A logistic regression model showed that the educational level of farmers and the elevation of farm location were associated with helminth infections.
\end{abstract}

Keywords: Risk Factors; Gastrointestinal Parasites; Sheep; Goats; Farm; Greece

\section{Introduction}

Small ruminant farming is an important economic activity for European countries, especially those with a temperate Mediterranean environment and particularly for Greece. Sheep and goats are infected with the same principal gastrointestinal nematode species, which provoke similar pathological changes and economic consequences [1]. The parasitism with helminths, and particularly nematodes of the gastrointestinal tract, is a major threat for ruminant production, health and welfare associated with outdoor breeding [2]. Specifically, gastrointestinal (GI) parasites are one of the main constraints to small ruminant production in temperate countries [3] and may amount to $20 \%$ loss for marketable products [4]. The traditional sheep production system in Greece is extensive without transhumance where sheep stay in permanent installations near the villages and graze nearby [5]. Control of helminths in Greece is currently based exclusively on the frequent use of anthelmintics. However, the appearance of anthelmintic resistance in Greece [6,7]

"Corresponding author. indicates the need for control strategies targeting only animals at high risk for GI infections in order to limit the use of anthelmintic drugs and conserve their efficacy.

Previous studies have investigated the epidemiology and importance of GI parasitic infections in small ruminants, but few studies have addressed the role of animal, farm, and environmental factors in relation to the presence of GI parasitic infections in small ruminants in the Mediterranean area [8-11]. The objective of the present study was to examine the animal, farm, and environment related factors that may affect the risk for GI parasitic infections of small ruminants in Greece, where no previous studies have been reported.

\section{Materials and Methods}

\subsection{Animals and Sampled Areas}

Fecal samples were collected from clinically healthy and randomly selected sheep and goats in organic and neighboring conventional farms. These farms are registered with the Hellenic Ministry of Rural Development 
and Food according to the latest available census (2005) in the region of Thessaly, Greece. The region of Thessaly is located in Central Greece (Figure 1). It is one of the largest sheep and goat producing areas of Greece and accounts for $12.5 \%$ of the total sheep and goat production in Greece (data for 2006 provided by the National Statistical Service of Greece). In addition, $28 \%$ of organic sheep and goat farming in Greece is located in Thessaly (data for 2005 provided by the Hellenic Ministry of Rural Development and Food). Thessaly is generally affected by a temperate Mediterranean climate which is characterized by dry summers with occasional precipitation and calm, wet winters. There are droughts during the summer months.

Farms whose owners agreed to participate in the study were visited once between September 2006 and February 2007 and were equally distributed by autumn and winter seasons. Fecal samples $(10-20 \mathrm{~g})$ were collected directly from the rectum of the animals and stored at $4^{\circ} \mathrm{C}$ until analyzed. Data on animal characteristics, farm management practices, and farmer status were collected through a survey questionnaire at the time of sampling. Data were collected via a 2-page questionnaire comprising 10 closed questions. In order to avoid any misunderstanding, the investigators completed the questionnaires by interviewing the farmers at the time of the visit to the farm for sample collection. The questionnaire with pre-coded replies is available on request by e-mail.

\subsection{Parasitological Analyses}

Fecal egg counts (epg) were conducted using the McMaster method [12] separating strongyle-type eggs, $\mathrm{Ne}$ matodirus spp., Trichuris spp., Fasciola hepatica, Dicrocoelium dendriticum eggs, and coccidian oocyts. The flotation medium used for nematode and cestode eggs was sugar solution with a specific gravity of 1.2 , while for trematode eggs was zinc sulphate with a specific gravity of 1.5. To increase the accuracy of the McMaster method four chambers per sample were enumerated.

\subsection{Source of Environmental Data}

Environmental data for farm locations were obtained from the MODIS (Moderate Resolution Imaging Spectroradiometer) instrument aboard the Terra (EOS AM) satellite (https://lpdaac.usgs.gov/), products MOD13C2 and MOD11C3, with a resolution of $0.05 \mathrm{deg}$ for the land surface temperature (LST) and the normalized difference vegetation index (NDVI). Rainfall data was extracted from the 3B43 rainfall product of the Tropical Rainfall Measuring Mission (TRMM) satellite (http://disc2.nascom.nasa.gov/) with a resolution of $0.25 \mathrm{deg}$. NDVI and LST were hypothesized to represent surrogate measures of environmental moisture and temperature, respectively [13]. The environmental data were recorded as monthly means for 12 months before the day of sampling for each examined farm. Geographical coordinates and elevation data of farm locations were obtained from the Digital Elevation Model (DEM), SRTM30 dataset for Greece with a resolution of $1 \mathrm{~km}$ and CGIAR-SRTM data (http:// srtm.csi.cgiar.org/) aggregated to 30 seconds. The inland water digital chart of the world (http://www.diva-gis. org/gdata) was used for the construction of the geographic features of Thessaly.

\subsection{Statistical Analysis}

The relationship between the prevalence of helmith infections and the investigated factors was analyzed by defining a binary outcome variable where positives samples (as determined by coprological examination) were coded as 1 , while negative samples were coded as 0 .

The Chi-square test was used to analyze the association of all examined factors as independent categorical variables with helminth and coccidian prevalence. Vari-

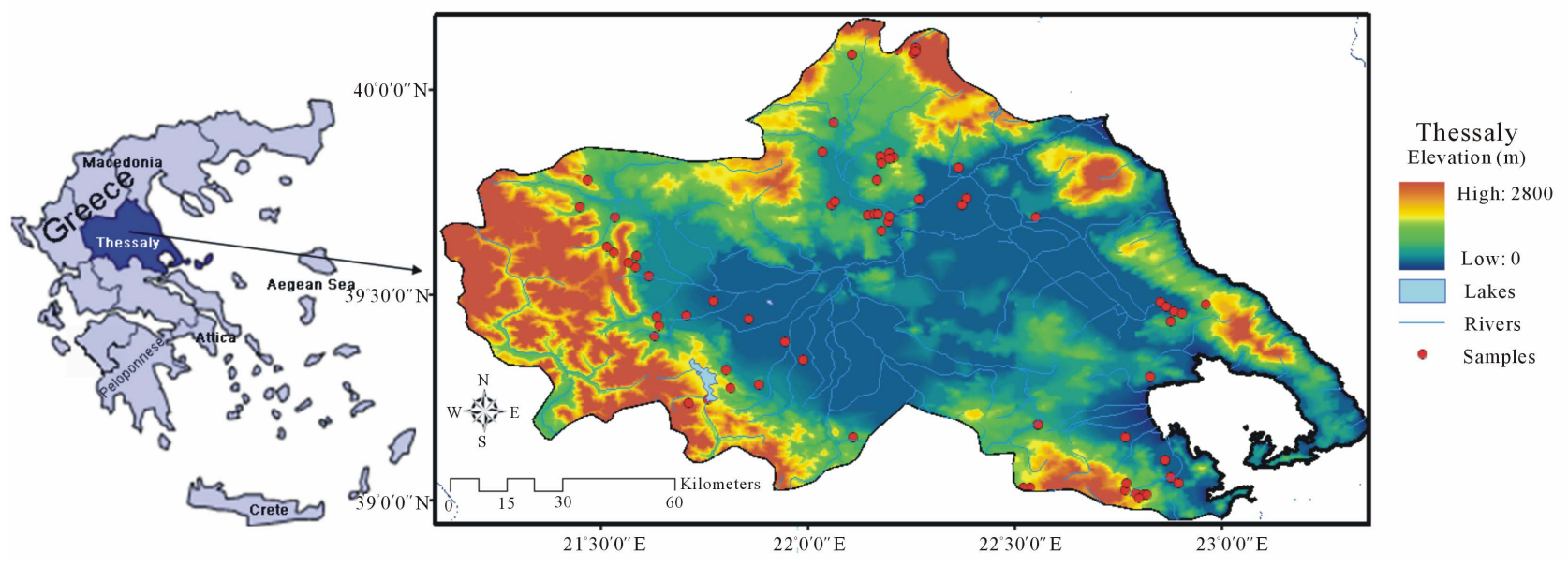

Figure 1. Geographical features of Thessaly, Greece. 
ables significant at $\mathrm{p}<0.05$ were tested for multicolinearity and selected for inclusion in the multivariate logistic regression model. Overall fit of the logistic regression models was assessed using the Hosmer-Lemeshow goodness-of-fit statistics. Results are presented as adjusted odds ratios (OR) with $95 \%$ confidence intervals $(95 \%$ CI). In all cases, the statistical significance was considered at 5\% level. Missing observations were excluded from the analysis. All statistics were performed using the SPSS version 13.0 statistical package.

\section{Results}

A total of 31 organic farms (12\% of all organic sheep and goat farms in Thessaly) and 38 neighboring conventional farms agreed to participate in the study. In total 557 fecal samples from sheep and goats belonging to 69 farms were collected. Helminth eggs were detected in 44 (7.9\%) samples. Strongyle-type eggs were found in 19 (3.4\%) samples, Nematodirus spp. eggs in $6(1.1 \%)$ samples, Trichuris spp. eggs in 16 (2.9\%) samples, Fasciola hepatica in $3(0.5 \%)$ samples, and Dicrocoelium dendriticum in $1(0.2 \%)$ sample. Coccidian oocysts were found in $36(6.5 \%)$ samples (Table $\mathbf{1})$.

Univariate analysis of animal and farm-related factors (Table 2), grazing and farmer characteristics-related factors (Table 3) and environment-related factors (Table 4) showed that the rotation of grazing pastures, educational level of farmers, normalized difference vegetation index (NDVI) of farm location, and the elevation of farm location were associated with helminth infections. None of the examined factors was associated with coccidian infections (Tables 5-7). These significant factors were simultaneously analyzed in a logistic regression model to assess their relative contribution to helminth infections prevalence, while adjusting for their effects. The final logistic regression model showed that the educational level of farmers and the elevation of farm location were associated with helminth infections (Table 8). The risk of helminth infections in small ruminants was more than three-fold higher for farms owned or managed by farmers with a low educational level (elementary school or lower), compared with farms tended by farmers with a high level of education (middle school up to university) $(p<0.05)$. The risk of helminth infections was 0.36 -fold lower for small ruminants in farms located in semimountainous areas compared to farms located in plain or mountainous areas $(\mathrm{p}<0.02)$.

\section{Discussion}

The present study is the first epidemiological investigation of factors associated with GI parasitic infections of sheep and goats in Greece under a temperate Mediterranean climate. Therefore, the findings of this study can be generalized to other sheep and goat farms in areas with similar climatic conditions and management.

The spectrum of the GI parasites observed in sheep and goats in Greece comprised strongyles, Nematodirus spp., Trichuris spp. and coccidia at low to moderate prevalence. Fasciola hepatica and Dicrocoelium dendriticum were sporadically found, contrary to previous studies in Greece where the prevalence was higher on the basis of carcass inspection [14] and coproantigen or ELISA [11].

No significant risk factors were identified in the present study in regard to the presence of coccidian infections in sheep and goats. Nevertheless, studies under Mediterranean weather have shown a high prevalence of coccidian infections in lambs and goat kids $[15,16]$ and adult animals [17]. Also, animal species was found to be another risk factor in a study in South Africa, where the mean monthly oocysts per gram of feces for goats was significantly higher than that for sheep [18].

Table 1. Prevalence (\%) of gastrointestinal parasitic infections in small ruminants in Thessaly region, Greece.

\begin{tabular}{|c|c|c|c|c|c|c|c|c|c|c|}
\hline \multirow[b]{3}{*}{ Infection } & \multicolumn{10}{|c|}{ Prefecture } \\
\hline & \multicolumn{2}{|c|}{ Thessaly $(\mathrm{N}=557)$} & \multicolumn{2}{|c|}{ Trikala $(\mathrm{N}=80)$} & \multicolumn{2}{|c|}{ Karditsa $(\mathrm{N}=105)$} & \multicolumn{2}{|c|}{ Larissa (N = 202) } & \multicolumn{2}{|c|}{ Magnisia $(\mathrm{N}=170)$} \\
\hline & $\mathrm{n}$ & $\%(95 \% \mathrm{CI})$ & $\mathrm{n}$ & $\%(95 \% \mathrm{CI})$ & $\mathrm{n}$ & $\%(95 \% \mathrm{CI})$ & $\mathrm{n}$ & $\%(95 \% \mathrm{CI})$ & $\mathrm{n}$ & $\%(95 \% \mathrm{CI})$ \\
\hline Helminths* & 44 & $7.9(5.9-10.5)$ & 8 & $10(4.4-18.8)$ & 13 & $12.4(6.8-20.2)$ & 9 & $4.5(2.1-8.3)$ & 14 & $8.2(4.6-13.4)$ \\
\hline Strongyles & 19 & $3.4(2.1-5.4)$ & 3 & $3.8(0.8-10.6)$ & 4 & $3.8(1-9.5)$ & 7 & $3.5(1.4-7)$ & 5 & $2.9(1-6.7)$ \\
\hline Nematodirus spp. & 6 & $1.1(0.4-2.5)$ & 0 & $0(0-4.5)$ & 2 & $1.9(0.2-6.7)$ & 0 & $0(0-1.8)$ & 4 & $2.4(0.6-5.9)$ \\
\hline Trichuris spp. & 16 & $2.9(1.7-4.7)$ & 4 & $5(1.4-12.3)$ & 5 & $4.8(1.6-10.8)$ & 0 & $0(0-1.8)$ & 7 & $4.1(1.7-8.3)$ \\
\hline Fasciola hepatica & 3 & $0.5(0.1-1.7)$ & 2 & $2.5(0.3-8.7)$ & 1 & $1(0-5.2)$ & 0 & $0(0-0.8)$ & 0 & $0(0-2.1)$ \\
\hline Dicrocoelium dendriticum & 1 & $0.2(0-1.2)$ & 0 & $0(0-4.5)$ & 1 & $1(0-5.2)$ & 0 & $0(0-0.8)$ & 0 & $0(0-2.1)$ \\
\hline Coccidia & 36 & $6.5(4.6-8.9)$ & 3 & $3.8(0.8-10.6)$ & 5 & $4.8(1.6-10.8)$ & 14 & $6.9(3.8-11.4)$ & 14 & $8.2(4.6-13.4)$ \\
\hline
\end{tabular}

*: Infection with all the investigated parasites except coccidian; CI: Confidence interval. 
Table 2. Univariate analysis of various animal host and farm-related risk factors associated with helminth infections in small ruminants. Results are presented as odd ratios (OR) and $95 \%$ confidence intervals (CI).

\begin{tabular}{|c|c|c|c|c|c|c|}
\hline Factor & $\mathrm{N}$ & $\mathrm{n}$ & Prevalence $(\%)$ & Crude OR & $95 \% \mathrm{CI}$ & p-value \\
\hline Species of small ruminant & & & & & & 0.44 \\
\hline Sheep & 334 & 24 & 7.2 & 0.786 & $0.42-1.46$ & \\
\hline Goat & 223 & 20 & 9.0 & 1.00 & & \\
\hline Herd size (number of animals) & & & & & & 0.10 \\
\hline$<150$ & 124 & 15 & 12.1 & 2.202 & $1.06-4.56$ & \\
\hline $150-300$ & 107 & 9 & 8.4 & 1.47 & $0.63-3.40$ & \\
\hline$>300$ & 289 & 17 & 5.9 & 1.00 & & \\
\hline Unknown & 37 & & & & & \\
\hline Farm type & & & & & & 0.69 \\
\hline Organic & 269 & 20 & 7.4 & 0.88 & $0.47-1.63$ & \\
\hline Conventional & 288 & 24 & 8.3 & 1.00 & & \\
\hline Anthelmintic treatment & & & & & & 0.27 \\
\hline No & 116 & 12 & 10.3 & 1.47 & $0.73-2.96$ & \\
\hline Yes & 441 & 32 & 7.3 & 1.00 & & \\
\hline Class of anthelmintic treatment & & & & & & 0.14 \\
\hline No anthelmintic & 117 & 12 & 10.3 & - & - & \\
\hline Albendazole & 388 & 26 & 6.7 & - & - & \\
\hline Other benzimidazoles & 11 & 1 & 9.1 & - & - & \\
\hline Imidazothiazoles & 23 & 5 & 21.7 & - & - & \\
\hline Salicylanilides & 18 & 0 & 0 & - & - & \\
\hline
\end{tabular}

Table 3. Univariate analysis of various grazing and farmer characteristics-related risk factors associated with helminth infections in small ruminants. Results are presented as odd ratios (OR) and $95 \%$ confidence intervals (CI).

\begin{tabular}{|c|c|c|c|c|c|c|}
\hline Factor & $\mathrm{N}$ & $\mathrm{n}$ & Prevalence $(\%)$ & Crude OR & $95 \% \mathrm{CI}$ & p-value \\
\hline Grazing of animals & & & & & & 0.88 \\
\hline No & 11 & 1 & 9.1 & 1.17 & $0.14-9.35$ & \\
\hline Yes & 546 & 43 & 7.9 & 1.00 & & \\
\hline Grazing with other herds & & & & & & 0.25 \\
\hline Grazing alone/no contact & 104 & 6 & 5.8 & 0.923 & $0.33-2.54$ & \\
\hline Grazing with the same species & 241 & 24 & 10 & 1.66 & $0.81-3.42$ & \\
\hline Grazing with sheep, goats, cattle, pigs, and horses & 193 & 12 & 6.2 & 1.00 & & \\
\hline Unknown & 19 & & & & & \\
\hline Rotation of grazing & & & & & & 0.04 \\
\hline No & 455 & 40 & 8.8 & 3.90 & $0.92-16.4$ & \\
\hline Yes & 83 & 2 & 2.4 & 1.00 & & \\
\hline Unknown & 19 & & & & & \\
\hline Age of farmer (years) & & & & & & 0.06 \\
\hline $18-44$ & 227 & 12 & 5.3 & 0.52 & $0.26-1.03$ & \\
\hline$\geq 45$ & 330 & 32 & 9.7 & 1.00 & & \\
\hline Educational level of farmer & & & & & & 0.03 \\
\hline Basic level (elementary school or lower) & 405 & 38 & 9.4 & 2.52 & $1.04-6.08$ & \\
\hline High level (middle school up to university) & 152 & 6 & 3.9 & 1.00 & & \\
\hline
\end{tabular}


Table 4. Univariate analysis of various environment-related risk factors associated with helminth infections in small ruminants. Results are presented as odd ratios (OR) and $95 \%$ confidence intervals (CI).

\begin{tabular}{|c|c|c|c|c|c|c|}
\hline Factor & $\mathrm{N}$ & $\mathrm{n}$ & Prevalence (\%) & Crude OR & $95 \% \mathrm{CI}$ & p-value \\
\hline Season & & & & & & 0.11 \\
\hline Autumn & 292 & 18 & 6.2 & 0.60 & $0.32-1.12$ & \\
\hline Winter & 265 & 26 & 9.8 & 1.00 & & \\
\hline Land surface temperature (C) & & & & & & 0.05 \\
\hline$\leq 15$ & 215 & 23 & 10.7 & 1.83 & $0.98-3.39$ & \\
\hline$>15$ & 342 & 21 & 6.1 & 1.00 & & \\
\hline NDVI & & & & & & 0.02 \\
\hline Low vegetation $(0.40-0.50)$ & 223 & 9 & 4.0 & 0.37 & $0.15-0.90$ & \\
\hline Moderate vegetation $(0.50-0.60)$ & 216 & 23 & 10.6 & 1.03 & $0.50-2.20$ & \\
\hline Dense vegetation $(>0.60)$ & 118 & 12 & 10.2 & 1.00 & & \\
\hline Rain (mm) & & & & & & 0.95 \\
\hline $450-600$ & 148 & 11 & 7.4 & 0.88 & $0.39-1.96$ & \\
\hline $600-800$ & 217 & 17 & 7.8 & 0.93 & $0.45-1.90$ & \\
\hline$>800$ & 192 & 16 & 8.3 & 1.00 & & \\
\hline Elevation of farm location (m) & & & & & & 0.01 \\
\hline Plain $(1-200)$ & 217 & 17 & 7.8 & 0.49 & $0.24-1.03$ & \\
\hline Semi-mountainous $(200-700)$ & 230 & 11 & 4.8 & 0.29 & $0.13-0.66$ & \\
\hline Mountainous (>700) & 110 & 16 & 14.5 & 1.00 & & \\
\hline Prefecture of farm location & & & & & & 0.09 \\
\hline Trikala & 80 & 8 & 10 & 1.23 & $0.49-3.08$ & \\
\hline Karditsa & 105 & 13 & 12.4 & 1.57 & $0.70-3.49$ & \\
\hline Larissa & 202 & 9 & 4.5 & 0.52 & $0.21-1.23$ & \\
\hline Magnisia & 170 & 14 & 8.2 & 1.00 & & \\
\hline
\end{tabular}

Table 5. Univariate analysis of various animal host and farm-related risk factors associated with coccidian infections in small ruminants. Results are presented as odd ratios (OR) and $95 \%$ confidence intervals (CI).

\begin{tabular}{|c|c|c|c|c|c|c|}
\hline Factor & $\mathrm{N}$ & $\mathrm{n}$ & Prevalence (\%) & Crude OR & $95 \% \mathrm{CI}$ & p-value \\
\hline Species of small ruminant & & & & & & 0.88 \\
\hline Sheep & 334 & 22 & 6.6 & 1.05 & $0.52-2.10$ & \\
\hline Goat & 223 & 14 & 6.3 & 1.00 & & \\
\hline Herd size (number of animals) & & & & & & 0.14 \\
\hline 150 & 124 & 5 & 4.0 & 0.67 & $0.242-1.86$ & \\
\hline$>150-300$ & 107 & 11 & 10.3 & 1.83 & $0.829-4.05$ & \\
\hline$>300$ & 289 & 17 & 5.9 & 1.00 & & \\
\hline Unknown & 37 & & & & & \\
\hline Farm type & & & & & & 0.63 \\
\hline Organic & 269 & 16 & 5.9 & 0.84 & $0.43-1.67$ & \\
\hline Conventional & 288 & 20 & 6.9 & 1.00 & & \\
\hline Anthelmintic treatment & & & & & & 0.52 \\
\hline No & 116 & 6 & 5.2 & 0.74 & $0.30-1.84$ & \\
\hline Yes & 441 & 30 & 6.8 & 1.00 & & \\
\hline Class of anthelmintic treatment & & & & & & 0.69 \\
\hline No anthelmintic & 117 & 6 & 5.1 & 0.43 & $0.08-2.32$ & \\
\hline Albendazole & 388 & 26 & 6.7 & 0.57 & $0.12-2.63$ & \\
\hline Other benzimidazoles & 11 & 0 & 0.0 & 0 & - & \\
\hline Imidazothiazoles & 23 & 2 & 8.7 & 0.79 & $0.97-6.08$ & \\
\hline Salicylanilides & 18 & 2 & 11.1 & 1.00 & & \\
\hline
\end{tabular}


Table 6. Univariate analysis of various grazing and farmer characteristics-related risk factors associated with coccidian infections in small ruminants. Results are presented as odd ratios (OR) and 95\% confidence intervals (CI).

\begin{tabular}{|c|c|c|c|c|c|c|}
\hline Factor & $\mathrm{N}$ & $\mathrm{n}$ & Prevalence $(\%)$ & Crude OR & $95 \% \mathrm{CI}$ & p-value \\
\hline Grazing of animals & & & & & & 0.15 \\
\hline No & 11 & 2 & 18.2 & 3.34 & $0.69-16.1$ & \\
\hline Yes & 546 & 34 & 6.2 & 1.00 & & \\
\hline Grazing with other herds & & & & & & 0.05 \\
\hline Grazing alone/no contact & 104 & 3 & 2.9 & 0.28 & $0.83-1.04$ & \\
\hline Grazing with the same species A & 241 & 12 & 5.0 & 0.5 & $0.23-1.08$ & \\
\hline Grazing with sheep, goats, cattle, pig and horses & 193 & 18 & 9.3 & 1.00 & & \\
\hline Unknown & 19 & & & & & \\
\hline Rotation of grazing & & & & & & 0.58 \\
\hline No & 455 & 29 & 6.4 & 1.34 & $0.46-3.93$ & \\
\hline Yes & 83 & 4 & 4.8 & 1.00 & & \\
\hline Unknown & 19 & & & & & \\
\hline Age of farmer (years) & & & & & & 0.64 \\
\hline $18-44$ & 227 & 16 & 7.0 & 1.17 & $0.59-2.32$ & \\
\hline$\geq 45$ & 330 & 20 & 6.1 & 1.00 & & \\
\hline Educational level of farmer & & & & & & 0.48 \\
\hline Basic level (elementary school or lower) & 405 & 28 & 6.9 & 1.33 & $0.59-3$ & \\
\hline High level (middle school up to university) & 152 & 8 & 5.3 & 1.00 & & \\
\hline
\end{tabular}

Table 7. Univariate analysis of various environment-related risk factors associated with coccidian infections in small ruminants. Results are presented as odd ratios (OR) and $95 \%$ confidence intervals (CI).

\begin{tabular}{|c|c|c|c|c|c|c|}
\hline Factor & $\mathrm{N}$ & $\mathrm{n}$ & Prevalence $(\%)$ & Crude OR & $95 \% \mathrm{CI}$ & p-value \\
\hline Season & & & & & & 0.09 \\
\hline Autumn & 292 & 14 & 4.8 & 0.55 & $0.27-1.12$ & \\
\hline Winter & 265 & 22 & 8.3 & 1.00 & & \\
\hline Land surface temperature $(\mathrm{C})$ & & & & & & 0.69 \\
\hline$\leq 15$ & 215 & 15 & 7.0 & 1.14 & $0.57-2.27$ & \\
\hline$>15$ & 342 & 21 & 6.1 & 1.00 & & \\
\hline NDVI & & & & & & 0.88 \\
\hline Low vegetation $(0.40-0.50)$ & 223 & 13 & 5.8 & 0.85 & $0.34-2.11$ & \\
\hline Moderate vegetation $(0.50-0.60)$ & 216 & 15 & 6.9 & 1.02 & $0.42-2.49$ & \\
\hline Dense vegetation $(>0.60)$ & 118 & 8 & 6.8 & 1.00 & & \\
\hline Rain (mm) & & & & & & 0.47 \\
\hline $450-600$ & 148 & 11 & 7.4 & 1.63 & $0.65-4.04$ & \\
\hline $600-800$ & 217 & 16 & 7.4 & 1.62 & $0.69-3.75$ & \\
\hline$>800$ & 192 & 9 & 4.7 & 1.00 & & \\
\hline Elevation of farm location (m) & & & & & & 0.80 \\
\hline Plain $(1-200)$ & 217 & 15 & 6.9 & 0.94 & $0.38-2.30$ & \\
\hline Semi-mountainous (200 - 700) & 230 & 13 & 5.7 & 0.76 & $0.30-1.90$ & \\
\hline Mountainous (>700) & 110 & 8 & 7.3 & 1.00 & & \\
\hline Prefecture of farm location & & & & & & 0.48 \\
\hline Trikala & 80 & 3 & 3.8 & 0.43 & $0.12-1.55$ & \\
\hline Karditsa & 105 & 5 & 4.8 & 0.55 & $0.19-1.59$ & \\
\hline Larissa & 202 & 14 & 6.9 & 0.83 & $0.38-1.79$ & \\
\hline Magnisia & 170 & 14 & 8.2 & 1.00 & & \\
\hline
\end{tabular}


Table 8. Logistic regression analysis of risk factors associated with helminth infections in small ruminants (final model, including both farm and environment-related factors).

\begin{tabular}{|c|c|c|c|c|c|c|}
\hline Factor & $\mathrm{N}$ & $\mathrm{n}$ & Prevalence (\%) & Adjusted OR & $95 \% \mathrm{CI}$ & p-value \\
\hline \multicolumn{7}{|l|}{ Rotation of grazing } \\
\hline No & 455 & 40 & 8.8 & 2.07 & $0.44-9.0$ & 0.36 \\
\hline Yes & 83 & 2 & 2.4 & 1.00 & & \\
\hline Unknown & 19 & & & & & \\
\hline \multicolumn{7}{|l|}{ Educational level of farmer } \\
\hline Basic level (elementary school or lower) & 405 & 38 & 9.4 & 3.13 & $1.13-8.62$ & 0.02 \\
\hline High level (middle school up to university) & 152 & 6 & 3.9 & 1.00 & & \\
\hline \multicolumn{7}{|l|}{ NDVI } \\
\hline Low vegetation $(0.40-0.50)$ & 223 & 9 & 4.0 & 0.39 & $0.13-1.10$ & 0.07 \\
\hline Moderate vegetation $(0.50-0.60)$ & 216 & 23 & 10.6 & 1.02 & $0.43-2.41$ & 0.95 \\
\hline Dense vegetation $(>0.60)$ & 118 & 12 & 10.2 & 1.00 & & \\
\hline \multicolumn{7}{|l|}{ Elevation of farm location (m) } \\
\hline Plain $(1-200)$ & 217 & 17 & 7.8 & 0.90 & $0.38-2.15$ & 0.82 \\
\hline Semi-mountainous (200 - 700) & 230 & 11 & 4.8 & 0.36 & $0.15-0.86$ & 0.02 \\
\hline Mountainous $(>700)$ & 110 & 16 & 14.5 & 1.00 & & \\
\hline
\end{tabular}

In the present study, animal species was not found to be a significant risk factor in regard to the presence of GI helminths, but in previous studies in Gambia [19] and Pakistan [20] it was found that goats carried significantly lower worm burdens than sheep.

Average NDVI of farm location for 12 months before sampling, which has been used as an indicator of regional thermal-moisture regimes, was the most significant environmental risk factor for GI helminth infections. NDVI values integrate a number of different environmental factors (land cover, temperature, rainfall, vapor pressure, etc.) into a single variable and thus simplify analysis [21]. In Sub-Saharan Africa, after adjusting for distance from the equator, low NDVI values are predictive of an increase in cryptosporidiosis in the following month [22]. On the contrary, in the present study, NDVI was not found to be a risk factor concerning coccidian infections.

The variables introduced into the statistical model that concern the age or the educational level of farmers had also been investigated by other authors in Italy [23] and in Kenya [24]. The educational level of farmer was an important risk factor of GI helminth infections in the present study. This finding is in agreement with reports from other investigators in Kenya [24]. It is known that a large part of the variation in the performance of livestock production is caused by the quality of the management-stockpeople team [25]. The low education level of farmers may be associated with a low degree of stockmanship and with a higher number of at-risk activities, such as the careless manipulation of offal, carcass, feces, water or feed in the farm, which favor the transmission of certain parasites [26].

Elevation of farm location was found in the present study to be a risk factor for GI helminth infections in sheep and goats. Farms located on high elevation had a higher prevalence of GI helminth infections. Apparently, high elevation areas have favorable climatic conditions for the development of the free-living stages of the GI nematodes. Elevation has also been found to be a risk factor for the presence of F. hepatica in sheep and goats in Greece where a significant correlation was detected between coproantigens of $F$. hepatica and elevation [11].

In conclusion, the present study provides the first epidemiological investigation of risk factors associated with GI helminth infections of sheep and goats in Greece. The emerging profile of sheep and goats at high risk for GI helminth infections in Greece is that of animals belonging to farms where the educational level of the farmer is low and the farm is located in a mountainous area with moderate vegetation. Therefore, increasing farmer awareness for worm control measures could be achieved through education of the farmers. In addition, these findings can be used to target high risk farms with appropriate control measure for GI helminth parasites of sheep and goats in Greece and other areas with similar climatic conditions.

\section{REFERENCES}

[1] H. Hoste, S. Sotiraki, S. Y. Landau, F. Jackson and I. Beveridge, "Goat-Nematode Interactions: Think Differently," Trends in Parasitology, Vol. 26, No. 8, 2010, pp. 376-381. doi:10.1016/j.pt.2010.04.007 
[2] H. Hoste and J. F. Torres-Acosta, "Non Chemical Control of Helminths in Ruminants: Adapting Solutions for Changing Worms in a Changing World," Veterinary Parasitology, Vol. 180, No. 1-2, 2011, pp. 144-154. doi:10.1016/j.vetpar.2011.05.035

[3] L. Rinaldi, V. Veneziano and G. Cringoli, "Dairy Goat Production and the Importance of Gastrointestinal Strongyle Parasitism," Transactions of the Royal Society of Tropical Medicine and Hygiene, Vol. 101, No. 8, 2007, pp. 745746. doi:10.1016/j.trstmh.2007.03.010

[4] L. Bellani, A. Mantovani, A. Mordenti and R. Restani, "Socio-Economic Effects of Parasitic Disease of Animals," Veterinaria Italiana, Vol. 11-12, 1974, pp. 501520.

[5] G. Zervas, "Quantifying and Optimizing Grazing Regimes in Greek Mountain Systems," Journal of Applied Ecology, Vol. 35, No. 6, 1998, pp. 983-986. doi:10.1111/j.1365-2664.1998.tb00019.x

[6] E. Papadopoulos, C. Himonas and G. C. Coles, "Anthelmintic Resistance of Sheep and Goat Gastrointestinal Nematodes," Proceedings of the 7th Hellenic Veterinary Congress, Thessaloniki, 28 November-1 December, 1996, p. 149.

[7] E. Papadopoulos, C. Himonas and G. C. Coles, "Drought and Flock Isolation May Enhance the Development of Anthelmintic Resistance in Nematodes," Veterinary Parasitology, Vol. 97, No. 4, 2001, pp. 253-259. doi:10.1016/S0304-4017(01)00435-6

[8] G. Theodoropoulos, G. Zervas, A. Kouneli, B. MartinezGonzales, G. Petrakos and J. Kostopoulos, "Seasonal Patterns of Strongyle Infections in Grazing Sheep under the Traditional Production System in the Region of Trikala, Greece," Veterinary Parasitology, Vol. 89, No. 4, 2000, pp. 327-335. doi:10.1016/S0304-4017(00)00215-6

[9] E. Gallidis, E. Papadopoulos, S. Ptochos, G. Arsenos, "The Use of Targeted Selective Treatments Against Gastrointestinal Nematodes in Milking Sheep and Goats in Greece Based on Parasitological and Performance Criteria," Veterinary Parasitology, Vol. 164, No. 1, 2009, pp. 53-58. doi:10.1016/j.vetpar.2009.04.011

[10] V. Musella, D. Catelan, L. Rinaldi, C. Lagazio, G. Cringoli and A. Biggeri, "Covariate Selection in Multivariate Spatial Analysis of Ovine Parasitic Infection," Preventive Veterinary Medicine, Vol. 99, No. 2-4, 2011, pp. 69-77. doi:10.1016/j.prevetmed.2010.11.012

[11] V. Kantzoura, M. K. Kouam, N. H. Demiris, N. H. Feidas and G. Theodoropoulos, "Risk Factors and Geospatial Modelling for the Presence of Fasciola Hepatica Infection in Sheep and Goat farms in the Greek Temperate Mediterranean Environment," Parasitology, Vol. 138, No. 7, 2011, pp. 926-938. doi:10.1017/S0031182011000436

[12] D. Thienpont, F. Rochette and O. F. J. Vanparijs, "Diagnosing Helminthiasis by Coprological Examination," Janssen Research Foundation, Beerse, 1986.

[13] J. B. Malone, J. M. Yilma, J. C. McCarroll, B. Erko, S. Mukaratirwa and X. Zhou, "Satellite Climatology and the Environmental Risk of Schistosoma mansoni in Ethiopia and East Africa," Acta Tropica, Vol. 79, No. 1, 2001, pp. 59-72. doi:10.1016/S0001-706X(01)00103-6
[14] G. Theodoropoulos, E. Theodoropoulou, G. Petrakos, V. Kantzoura and J. Kostopoulos, "Abattoir Condemnation due to Parasitic Infections and its Economic Implications in the Region of Trikala, Greece," Journal of Veterinary Medicine Series B, Vol. 49, No. 6, 2002, pp. 281-284. doi:10.1046/j.1439-0450.2002.00563.x

[15] A. C. Causapé, J. Quílez, C. Sánchez-Acedo, E. del Cacho and F. López-Bernad, "Prevalence and Analysis of Potential Risk Factors for Cryptosporidium parvum Infection in Lambs in Zaragoza (Northeastern Spain)," Veterinary Parasitology, Vol. 104, No. 4, 2002, pp. 287-298. doi:10.1016/S0304-4017(01)00639-2

[16] A. Saratsis, A. Joachim, S. Alexandros and S. Sotiraki, "Lamb Coccidiosis Dynamics in Different Dairy Production Systems," Veterinary Parasitology, Vol. 181, No. 24, 2011, pp. 131-138. doi:10.1016/j.vetpar.2011.04.027

[17] A. Torina, S. Dara, A. M. Marino, O. A. Sparagano, F. Vitale, S. Reale and S. Caracappa, "Study of Gastrointestinal Nematodes in Sicilian Sheep and Goats," Annals of the New York Academy of Sciences, Vol. 1026, 2004, pp. 187-194. doi:10.1196/annals.1307.028

[18] F. R. Bakunzi, S. N. Thwane, L. E. Motrei and B. M. Dzoma, "Diversity and Seasonal Occurrence of Eimeria Species in a Mixed Flock of Communally Reared Sheep and Goats in Mafikeng in the North West Province, South Africa," Journal of the South African Veterinary Association, Vol. 81, No. 3, 2010, pp. 148-150.

[19] T. Fritsche, J. Kaufmann and K. Pfister, "Parasite Spectrum and Seasonal Epidemiology of Gastrointestinal Nematodes of Small Ruminants in the Gambia," Veterinary Parasitology, Vol. 49, No. 2-4, 1993, pp. 271-283. doi:10.1016/0304-4017(93)90126-8

[20] M. N. Khan, M. S. Sajid, M. K. Khan, Z. Iqbal and A. Hussain, "Gastrointestinal Helminthiasis: Prevalence and Associated Determinants in Domestic Ruminants of District Toba Tek Singh, Punjab, Pakistan," Parasitology Research, Vol. 107, No. 4, 2010, pp. 787-794. doi:10.1007/s00436-010-1931-x

[21] S. I. Hay, M. J. Pacher and D. J. Rogers, "The Impact of Remote Sensing on the Study and Control of Invertebrate Intermediate Hosts and Vectors for Disease," International Journal of Remote Sensing, Vol. 18, No. 14, 1997, pp. 2899-2930. doi:10.1080/014311697217125

[22] J. S. Jagai, D. A. Castronovo, J. Monchak and E. N. Naumova, "Seasonality of Cryptosporidiosis: A Meta-Analysis Approach," Environmental Research, Vol. 109, No. 4, 2009, pp. 465-478. doi:10.1016/j.envres.2009.02.008

[23] G. Cringoli, L. Rinaldi, V. Veneziano, G. Capelli and J. B. Malone, "A Cross-Sectional Coprological Survey of Liver Flukes in Cattle and Sheep from an Area of Southern Italian Apennines," Veterinary Parasitology, Vol. 108, No. 2, 2002, pp. 137-143. doi:10.1016/S0304-4017(02)00183-8

[24] A. Odoi, J. M. Gathuma, C. K. Gachuiri and A. Omore, "Risk Factors of Gastrointestinal Nematode Parasite Infections in Small Ruminants Kept in Smallholder Mixed Farms in Kenya," BMC Veterinary Research, Vol. 3, 2007, p. 6. doi:10.1186/1746-6148-3-6

[25] P. R. English, O. Mcpherson, S. G. Deligeorgis, J. M. 
Vidal, C. Tarocco, F. Bertaccini and H. Sterten, "Evaluation of the Effects of Training Methodologies, Motivational Influences and Staff and Enterprise Development Initiatives for Livestock Industry Workers in Scotland, Greece, Spain, Italy and Norway on Livestock Performance and Indices of Animal Welfare," In: A. J. F. Russel, C. A. Morgan, C. J. Savory, M. C. Appleby and T. L. Lawrence, Eds., Farm Animal Welfare-Who Writes the Rules? British Society of Animal Science, Occasional
Publication, London, 1999, pp. 137-143.

[26] G. Theodoropoulos, P. Peristeropoulou, M. K. Kouam, V. Kantzoura and E. Theodoropoulou, "Survey of Gastrointestinal Parasitic Infections of Beef Cattle in Regions under Mediterranean Weather in Greece," Parasitology International, Vol. 59, No. 4, 2010, pp. 556-559. doi:10.1016/j.parint.2010.07.004 